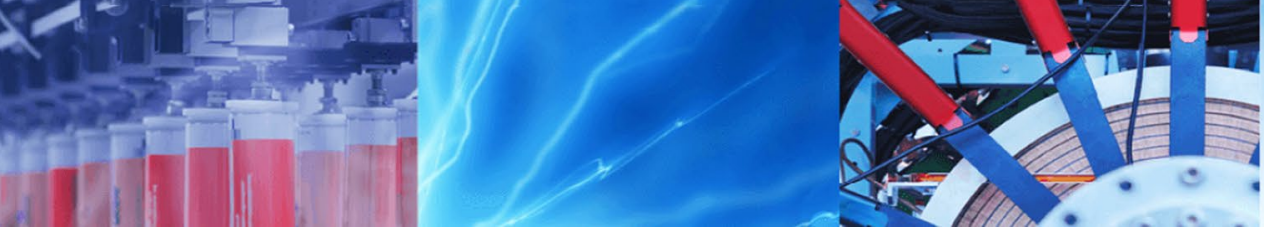

Research Article

\title{
Application of fuzzy analytic hierarchy process (FAHP) in failure investigation of knowledge-based business plans
}

\author{
Fatemeh Khorramrouz ${ }^{1}$ - Niloufar Pourmahdi Kajabadi ${ }^{1}$ Masoud Rahiminezhad Galankashi ${ }^{1,2}$ (I) . \\ Farimah Mokhatab Rafiei
}

(c) Springer Nature Switzerland AG 2019

\begin{abstract}
This research develops a fuzzy analytic hierarchy process (FAHP) to investigate and prioritize the failures of knowledgebased business plans. Although the concept of failure investigation has been discussed in previous studies, its integration with knowledge-based business plans is not investigated yet. To fill this gap, this research is completed in three main steps as follows. Firstly, the general failures of business are developed from the previous literature. Secondly, the developed failures are investigated with regard to their availability in knowledge-based business plans. Finally, a FAHP is applied to prioritize the failures of knowledge-based business plans. According to the obtained results, lack of managerial experience, lack of written business plans and ineffective advertising are the most important reason of failing knowledge-based business plans. As the major implications of this study, the developed measures, methodology and obtained results assist managers, researchers and investors to determine the sources of failures in knowledge-based business plans.
\end{abstract}

Keywords Failure investigation · Knowledge-based business plan · Fuzzy analytic hierarchy process (FAHP)

\section{Introduction}

Today's competitive markets include different businesses which might be local or international [28]. In this regard, new businesses must be very robust to compete with old businesses [32]. Therefore, it is critical to have a comprehensive business plan whenever a company is interested in entering to a new market [36]. As an important section of today's markets, knowledge-based companies are getting more attention especially in developing countries [2]. These companies contribute in increasing the knowledge of societies while maintaining their economic conditions. With the advent of business plans, managers and investors can see the upcoming events of a business before they decide to accept or reject those [23]. In this regard, a proper business plan can be considered as a win-win policy for both investors and new companies as it provides a proper opportunity to investigate, discuss and decide about the plan.

Although the concept of business plan has been investigated in previous literature [7], this is not sufficiently investigated in knowledge-based companies. In addition, the majority of previous studies have provided step by step procedure to start a new business [35] and neglected to investigate the different reasons of their failure. In other words, previous studies have approached the problem as a feasibility study or business plan and have not addressed the potential causes of the failures. In this regard, recognizing the potential causes of knowledge-based business failure, developing proper approaches to rank them and providing potential solutions to prevent these failures is a challenge which should be addressed.

There are numerous reasons which might cause to the failure of knowledge-based business plans. In addition,

\footnotetext{
$\triangle$ Masoud Rahiminezhad Galankashi, Masoud.Rahiminejad@yahoo.com | ${ }^{1}$ Department of Industrial, Mechanical and Aerospace Engineering, Buein Zahra Technical University, Buein Zahra, Qazvin, Iran. ${ }^{2}$ Department of Industrial Engineering, Tarbiat Modares University, Tehran, Iran.
} 
there are many criteria which might be used to determine the importance of these reasons. In this regard, the considered issue can be categorized as a Multiple-criteria decision making (MCDM) problem as there are different criteria and alternatives. There are numerous MCDM techniques which have been applied in previous literature [27]. As a well-known MCDM technique, analytic hierarchy process (AHP) has been significantly applied in recent studies [40]. However, similar to many MCDM techniques, AHP approach is basically a deterministic approach which cannot reflect the uncertainty and ambiguousness of decision makers. In other words, many decision makers prefer to express their judgments using linguistic variables which is not addressed in classic AHP. To deal with this concern, Fuzzy Analytic Hierarchy Process (FAHP) has been suggested as a useful approach to have the benefits of classic AHP while considering the uncertain and ambiguous environment of decision making $[16,18,19]$. The FAHP has been vastly applied and recommended in previous studies [37]. More related to our work, as this research aims to rank the major reasons of knowledge-based business plans' failures, the application of FAHP can be justified as it provides different decision making levels with numerous criteria to rank alternatives. In addition, this methodology can consider the linguistic expressions of decision makers in its final output [37]. Finally, while the nature of the considered problem of this study is probabilistic, it is less investigated in previous studies. This ignorance is mainly due to the intrinsic complexities of considering fuzzy values in decision making. Additionally, according to previous literature, many studies have successfully applied FAHP in similar research which can be considered as a proper justification to develop this methodology to business plan problems. Therefore, developing a FAHP to investigate and prioritize the failures of knowledge-based business plans is the main objective of this research. Following research questions are addressed in this study:

1. What are the major measures of prioritizing the failures of knowledge-based business plans?

2. What are the main reasons of failure in knowledgebased business plans?

3. How the FAHP can be applied to prioritize these reasons?

The scope of this study is limited to knowledge-based business plans of Iran. However, the framework, methodology, and the results can be applicable in other business areas. This research is developed to investigate the failures of knowledge-based business plans, along with addressing a FAHP to rank them. It suggests a novel method to determine the potential failures of knowledge-based business plans and prioritize them using a MCDM technique.
In other words, the general failures of business are determined and their availability are checked in knowledgebased business plans. From the academic and practical viewpoints, this research contributes to the literature since, to the best of authors' knowledge, no similar research is conducted in previous literature. The remainder of this research is structured as follows. Second section develops the related literature of the research. The research methodology is provided in Sect. 3. Following, Sect. 4 provides the results of this research. This Section is followed by concluding remarks. Some directions for future research are suggested in this Section.

\section{Literature review}

\subsection{Business}

Business is an entity that is individualistically operated. According to Harmon [26], any organization is interested in improving its business to enhance the ability of handling market dynamics and competition. Essentially, regarding the undeniable importance of business in economic system, it is crucial to investigate the major causes of business plans' failures [44]. The failure, its consequence and outputs has been vastly investigated in previous studies [6]. In addition, although these studies have worked on business failure and how it affects the behavior and performance of businesses, it is very critical to find the reason of failures which assist new start-ups or companies to avoid those [1]. The correct and timely investigation of the failures is the first step to survive and improve the performance of any business. Also, competition in the international environments, identification of the strong and weak points of the organization and business, and how to succeed in the complex business environment are undeniable issues in today's competitive markets $[16,18,19,46]$. Based on above mentioned facts, having a failure investigation system is crucial for any business development.

\subsection{Business failure}

The failure is probable to happen at all stages of developing a business [34]. According to previous studies on this subject, $50-90 \%$ of new businesses fail with regard to both micro and macro-economic issues [5]. As a definition provided by Martinez et al. [34], failure by closure, insolvency or liquidation refer to voluntary action of a business to be closed due to low quality performance. This action is done to assign resources more efficiently [50].

The primary causes of business failure include insufficient wealth and inadequate skills of top management [13]. According to contemporary financial principles, there 
is a connection among the expected return and failures. In other words, higher percentage of failure decreases the predictable yields. Consequently, it is significant to understand how the failure operates in this context.

There are two significant indicators which cooperatively define the failure rate of businesses. These factors include the effectiveness of management and the general economic environment [13]. Therefore, each unpredictable failure leads to the loss and subsequently failure of the business plan. Thus, failure investigation can be useful as it analyzes the current situation, determines the key issues, detects the improvable areas and finally creates the right basis for strategic planning. Therefore, developing a FAHP model to investigate the failures of knowledge-based business plans is the major aim of this study. By doing this, it efforts to find the potential failures of knowledge-based business plans and develop a MCDM approach to prioritize them. Next section discusses the previous related studies.

\subsection{Related studies}

As an undeniable issue in today's business, competitiveness should be considered in any industry, $[18,19,30,46]$. Nowadays, quality considerations, availability, cost saving issues, safety and reliability are getting more attention. Indeed, failure investigation is a wise choice to face this tough competition [15]. Based on Churchill [10], Ganguly [21] and Williams [52], failure is the discontinuance ownership of the business. According to Frank [15], fault is a synonym for failures, mistakes, errors or conflicts in the functional units leading to intolerable and undesirable behavior of the system. Choosing the most appropriate procedure, in addition to exploring the most common failures of knowledge-based business plans, relies on deeper investigation of failures [3]. Occasionally, a failure may cause a number of problems such as bankruptcy, financial failures and production losses [41]. Thus, the application of a failure investigation system becomes crucial [12]. In addition to cost reduction, the process availability, reliability and safety are the major responsibilities of any failure investigation system [4]. There are different types of failures in different business which are discussed as follows.

According to Cochran [11], there is no relevant and reliable data on failure rates of business. Business planning, risk management, social and financial motivation are common factors to prevent the failures of business [14]. According to Gaskill et al. [22], planning and managerial functions, growth, overexpansion and competitive environments are very critical in failure management. Everett and Watson [13] defined two principal reasons for failure in small business, namely the insufficient wealth and lack of proper management skills. Some studies consider the failure as the effect of external issues including the high rates of interest [25, 44]. Kazooba [31] developed a descriptive survey to determine the failure causes of small business. This research divided failures into two classes of internal factors (such as faulty product concept, wrong pricing, lack of planning, management problems, trouble among partners, poor report keeping, etc.) and external factors (poor market, taxation, and delays in processing application) in the system. According to Peterson et al. [44], failures are the direct consequence of lack of management expertise, high interest rates, taxes, competition, federal regulation and cash flow. Perry [43] investigated the planning's effect on failures of the business. Based on this study, business failures are the results of non-written business plans. As discussed, this study investigates the availability of business failures in knowledge-based business plans. A summary of current failures of business is provided in Table 1.

Bankruptcy and loss to creditors are the main criteria to prioritize different failures of businesses. In addition, further loss is another criteria which significantly affects the returnable profit [51]. Next criteria is financial failures. Inadequate keeping of financial records results in unreasonable return and other related problems of the system. As mentioned, failure investigation of knowledge-based business is not comprehensively investigated in previous research. However, following provides some of the related studies. Watson and Everett [51] defined small business failures by providing some appropriate criteria for selecting system in light of finding failures measure. Gunjal [24] provides a description on how knowledge management should be considered in business related activities. According to this research, corporates need to consider knowledge management in their processes. Kazooba [31] examined the major reasons of business failure in Uganda using expert-based opinion. According to the obtained results, taxation affects the business malfunction. The relationship between network knowledge and business has been investigated by Hohenthal et al. [29]. Particularly, this study investigated the relation among business and experience in foreign markets. Palacios-Marqués et al. [42] developed the previous literature on knowledge management and internet technology using web knowledge exchange approach. According to the obtained results, there is a negative relationship between web knowledge exchange and competition. According to Calvo-Mora et al. [8], process methodology, suppliers' involvement and partners are main factors of knowledge management which affects the business. Pina and Tether [45] contributed in developing a literature to identify the empirical knowledge bases. In addition, this study related their findings to different varieties which are available among Knowledge Intensive Business Services (KIBS). Xu et al. [53] developed a knowledge based approach to determine the relationship between big data, success of new product and 
Table 1 A review of current failures of business

\begin{tabular}{|c|c|c|c|c|c|c|c|c|}
\hline Failure cause & Index & Perry [43] & $\begin{array}{l}\text { Peterson } \\
\text { et al. [44] }\end{array}$ & $\begin{array}{l}\text { Gaskill } \\
\text { et al. } \\
{[22]}\end{array}$ & $\begin{array}{l}\text { Hall and } \\
\text { Young } \\
{[25]}\end{array}$ & Kazooba [31] & Cochran [11] & $\begin{array}{l}\text { Ferreira } \\
\text { et al. } \\
{[14]}\end{array}$ \\
\hline Lack of Social and financial motivation & $\mathrm{F} 1$ & & $\checkmark$ & & & $\checkmark$ & & $\checkmark$ \\
\hline Federal regulation & $\mathrm{F} 2$ & & $\checkmark$ & & & $\checkmark$ & & \\
\hline Cash flow & F3 & & $\checkmark$ & $\checkmark$ & & $\checkmark$ & & $\checkmark$ \\
\hline $\begin{array}{l}\text { Poor market research and faulty product con- } \\
\text { cept }\end{array}$ & $\mathrm{F} 4$ & & & $\checkmark$ & & $\checkmark$ & & \\
\hline Lack of experience & F5 & & & $\checkmark$ & & $\checkmark$ & & $\checkmark$ \\
\hline Lack of information & F6 & & & $\checkmark$ & & & $\checkmark$ & $\checkmark$ \\
\hline High interest rate & F7 & & $\checkmark$ & $\checkmark$ & $\checkmark$ & $\checkmark$ & & \\
\hline taxation & F8 & & $\checkmark$ & & & $\checkmark$ & & \\
\hline Trouble among partners & F9 & & & & & $\checkmark$ & & \\
\hline Growth and overexpansion & F10 & & & $\checkmark$ & & & & \\
\hline Competitive environment & $\mathrm{F} 11$ & & & $\checkmark$ & & $\checkmark$ & & \\
\hline Inadequate financial record keeping & $\mathrm{F} 12$ & & & $\checkmark$ & & $\checkmark$ & & \\
\hline Lack of knowledge on current business literature & $\mathrm{F} 13$ & & & $\checkmark$ & & & & \\
\hline Inadequate knowledge of pricing strategies & $\mathrm{F} 14$ & & & $\checkmark$ & & $\checkmark$ & & \\
\hline Lack of written business plan & F15 & $\checkmark$ & & $\checkmark$ & & & & \\
\hline Lack of managerial experience & F16 & & $\checkmark$ & $\checkmark$ & & $\checkmark$ & & \\
\hline Ineffective advertising & F17 & & & $\checkmark$ & & & & \\
\hline
\end{tabular}

traditional marketing. Riis et al. [47] developed an experimental study to increase the knowledge on ill-structured and complex problems of forming new business. As an important finding of this study, the engineering education should be more focused in organizational learning.

Kusumaningrum and Hidayat [33] provided the development process of a business plan using a production-oriented learning methodology. According to the obtained results, business plan on a product-based learning assists managers to maximize the predicted outputs of the products. In a recent study, Muñoz-Izquierdo et al. [41] explained the causes of business failure using logistic regression. According to this research, improper keeping of records is the common reason for failure of the business. Previous studies on this area are rare. However, a summary of previous studies is provided in Table 2. According to the highlights of the previous studies provided in Sect. 2, failure investigation is less reviewed in the previous literature. In addition, the importance of failures and their prioritization in knowledge-based business plans is neglected. To address the shortages of the previous literature, this research is carried out to investigate and prioritize the failures of knowledge-based business plans.

\subsection{Summary and identification of research gap}

In summary, according to the highlights of previous studies discussed in previous sections, an efficient approach to prioritize the failures of knowledgebased business plans is not developed yet, especially

Table 2 A summary of related studies

\begin{tabular}{|c|c|c|}
\hline References & Finding & Advantage \\
\hline Watson and Everett [51] & $\begin{array}{l}\text { Defining small business failure. The results are dedi- } \\
\text { cated to classify failures }\end{array}$ & Usage of criteria to select failure measures \\
\hline Gaskill et al. [22] & $\begin{array}{l}\text { Investigates business failure. The community of busi- } \\
\text { ness can be useful in light of failure reduction }\end{array}$ & Control data validation by applying variance method \\
\hline Everett and Watson [13] & $\begin{array}{l}\text { The obtained results indicate the importance of } \\
\text { economic factors }\end{array}$ & $\begin{array}{l}\text { Seeking the effect of macro-economic aspects on } \\
\text { failures of business }\end{array}$ \\
\hline Perry [43] & $\begin{array}{l}\text { Importance of written business plan on business } \\
\text { mortality }\end{array}$ & $\begin{array}{l}\text { Comparison between written and non-written business } \\
\text { plans }\end{array}$ \\
\hline Muñoz-Izquierdo et al. [41] & $\begin{array}{l}\text { Much of the existing failures are caused by improper } \\
\text { accounting reports }\end{array}$ & Using logical regression method \\
\hline
\end{tabular}


in developing countries where these topics are very new and need to be more investigated. In addition, the previous studies have approached the problem from a feasibility study perspective. In other words, the majority of previous studies have addressed the problem of constructing a new business and neglected to focus on different reasons which might contribute in failure of a business. Next, a MCDM technique is required to prioritize the potential reasons of failure as the importance of them can help managers, investors, practitioners and researcher to provide potential solutions. Lastly, as the majority of decision making problems occur in uncertain environments, it is required to combine MCDM techniques with fuzzy logic. Therefore, a FAHP is applied to rank different failures of knowledge-based business failure. This study seems to be the first application of FAHP in prioritizing the different failures of business plans, since, to be best of authors' knowledge, no comparable studies have been conducted before.

\section{Research methodology}

This section provides the research methodology by discussing the different steps of study. Figure 1 displays the overall procedure of research methodology. This Figure indicates how the bankruptcy, financial failures, purpose loss and unreasonable return can be applied as decision criteria to be integrated with FAHP. Next, the required steps of each phase is comprehensively discussed.
Step 1: Initial idea, literature review and gap identification

This research develops a FAHP to prioritize the most important reasons of knowledge-based business plans' failure. In spite of the availability of researches in this area, according to the conducted literature review, this concept is not investigated in knowledge-based business plans. Therefore, this step chooses the criteria to prioritize the most important failures of knowledge-based business plans. Figure 2 displays the structure of the FAHP model. According to this Figure, four major criteria of bankruptcy, financial failures, unreasonable return and purpose loss are applied to prioritize the faults of knowledge-based business plans. So, in summary, the first step aims to recognize and extract the common criteria to prioritize the failures of knowledge-based business plans.

Step 2: Determining the potential failures of knowledge-based business

A review of current failures of business is tabulated in Table 1. Based on this table, lack of social and financial motivation, federal regulation, cash flow, poor market research, lack of experience, lack of information, high interest rate, taxation, faulty product concept, trouble among partners, growth and overexpansion, competitive environment, inadequate financial record keeping, lack of knowledge on current business literature, inadequate knowledge of pricing strategies, lack of business plan, lack of managerial experience and ineffective advertising
Fig. 1 Research procedure

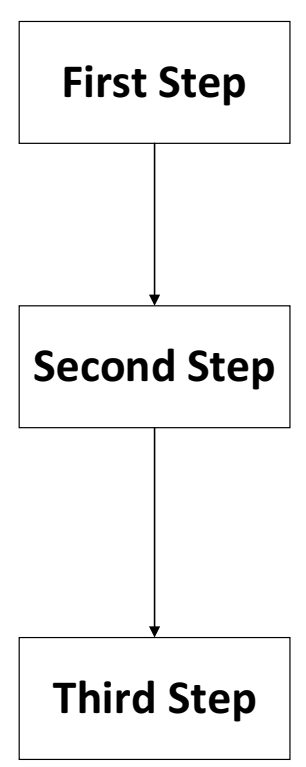

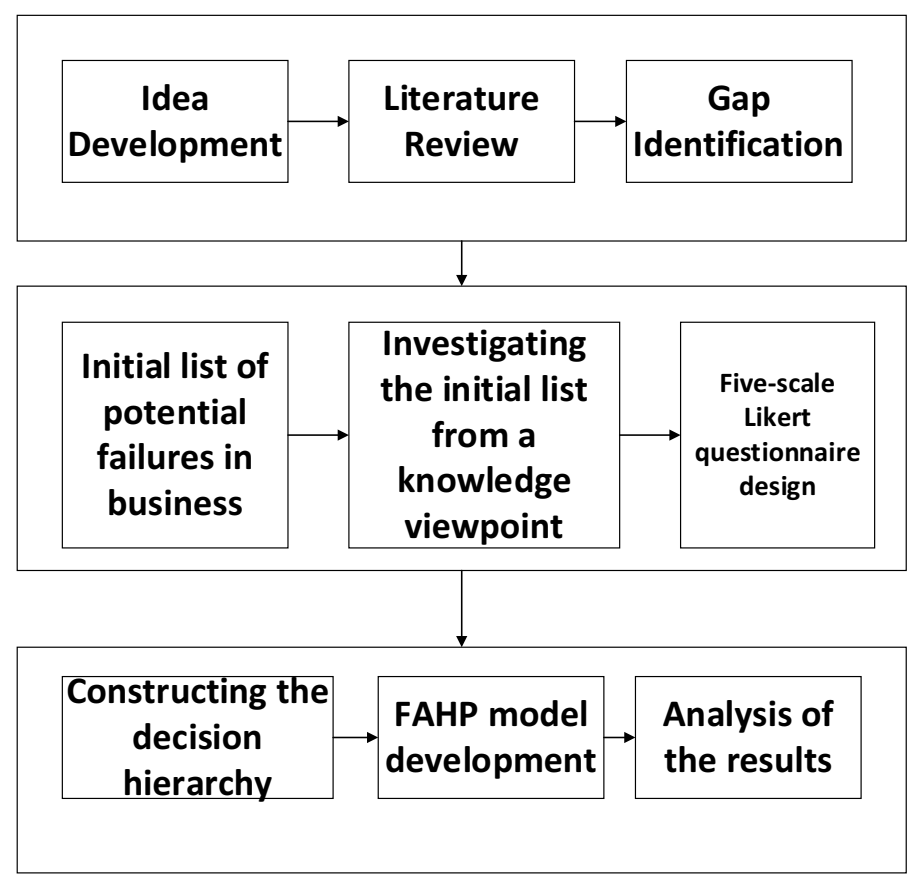

SN Applied Sciences A SPRINGER NATURE journal 


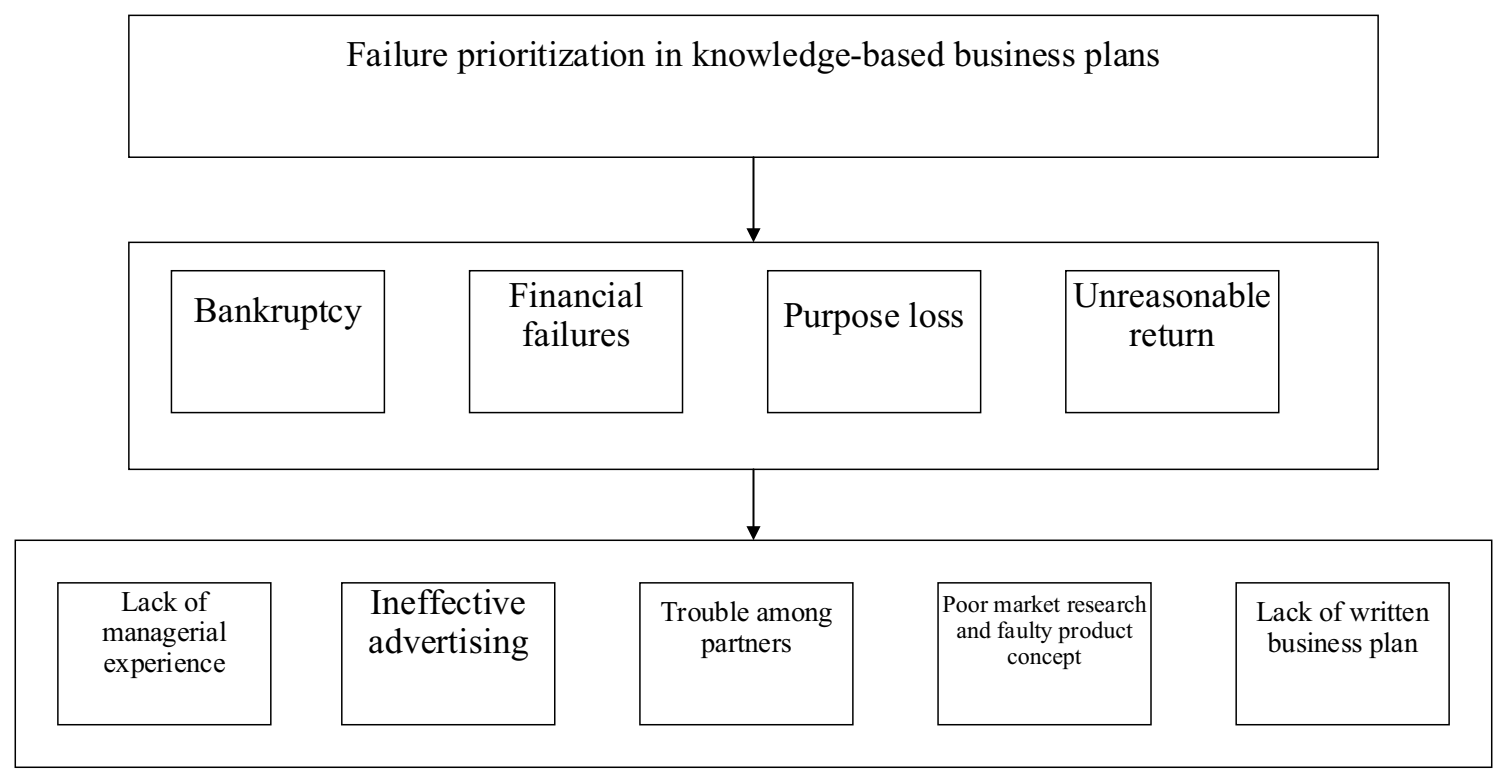

Fig. 2 FAHP hierarchy

are general failures of businesses. As there are many failures available in various businesses, an initial filtering is conducted to check which failures are more common in knowledge-based business. Therefore, a questionnaire is designed based on the current failures of business provided in Table 1. A five-scale Likert questionnaire is applied to determine the common failures of knowledge-based business plans.

\section{Step 3: Development of the FAHP model}

As discussed, the prioritization process should be conducted using a MCDM technique. There are different approaches which can be considered to rank/select alternatives using numerous decision making criteria [39]. These approaches include deterministic and stochastic methods which might be applied with regard to the nature of the considered problem. More related to the addressed problem of this research, there are four criteria to be considered in prioritizing five alternatives. Although a deterministic approach like AHP can be a proper approach to rank these alternatives, it is recommended to integrate it with fuzzy logic to be more realistic. In other words, today's complex decision making processes mostly happen in uncertain environments where the decision makers prefer to express their judgments using linguistic variables. Therefore, as an accepted alternative of AHP, the FAHP can cover all these issues. This methodology has been vastly investigated in previous studies focusing on different area of knowledge [38]. So, in summary as there are many problems considering different criteria to make the final decision [17, 27], MCDM approaches are supportive for concurrent consideration of all these criteria [16, 48, 54]. The decision hierarchy of this research includes three levels. The first level aims to prioritize the most important reasons of knowledge-based business plans failure. The second level includes the decision criteria which are bankruptcy, financial failures, purpose loss and unreasonable return. These four criteria are applied to rank the alternatives. The alternatives include lack of managerial experience, poor market research and faulty product concept, ineffective advertising, trouble among partners and lack of written business plan as shown in Fig. 2. The Chang' [9] extended analysis is applied to prioritize the failures of knowledge-based business plans as follows:

$M_{i j}=\left(l_{i j}, m_{i j}, u_{i j}\right)$

$I_{i j}=\min \left(B_{i j k}\right)$

$m_{i j}=\sqrt[n]{\prod_{k=1}^{n} B_{i j k}}$

$u_{i j}=\max \left(B_{i j k}\right)$

In which, triangular fuzzy numbers (TFNs) are presented by $\mathrm{L}, \mathrm{M}$ and $\mathrm{U} . K_{\text {th }}$ decision makers' score to determine the importance of $C_{i}-C_{j}$ is shown by Bijk. Subsequently, $C_{i}-C_{j}$ displays the decision criteria of FAHP. The related equation to conduct the necessary calculations of $M_{1}$ and $M_{2}$ are shown in following Equations: 
$M_{1}+M_{2}=\left(I_{1}+I_{2}, m_{1}+m_{2}, u_{1}+u_{2}\right)$

$M_{1} * M_{2}=\left(I_{1} * I_{2}, m_{1} * m_{2}, u_{1} * u_{2}\right)$

$M_{1}^{-1}=\left(\frac{1}{u_{1}}, \frac{1}{m_{1}}, \frac{1}{l_{1}}\right), M_{2}^{-1}=\left(\frac{1}{u_{2}}, \frac{1}{m_{2}}, \frac{1}{l_{2}}\right)$

In which, $M_{1}^{-1}$ and $M_{2}^{-1}$ show the inverse quantities of $M_{1}$ and $M_{2}$, respectively. Equation (8) is applied to calculate $S_{k}$ as follows:

$S_{k}=\sum_{j=1}^{n} M_{k j} *\left[\sum_{i=1}^{m} \sum_{j=1}^{n} M_{i j}\right]^{-1}$

The possibility degrees of $S_{k}$ should be calculated in next step. Similar calculation should be conducted for $M_{1}$ and $M_{2}$ as shown in following Equations.

$\left\{\begin{array}{ll}v\left(M_{1} \geq M_{2}\right)=1 & \text { if } M_{1} \geq M_{2} \\ V\left(M_{1} \geq M_{2}\right)=0 & \text { if } L_{1} \geq U_{2} \\ V\left(M_{1} \geq M_{2}\right)=\operatorname{hgt}\left(M_{1} \cap M_{2}\right) & \text { otherwise }\end{array}\right\}$

$\operatorname{hgt}(M 1 \cap M 2)=\frac{u_{1-} I_{2}}{\left(u_{1}-I_{2}\right)+\left(m_{2}-m_{1}\right)}$

A convex fuzzy number's possibility degree to be bigger than $\mathrm{k}$ convex fuzzy numbers is computed using Eq. (11).

$V\left(M_{1} \geq M_{2} \ldots M_{k}\right)=V\left(M_{1} \geq M_{2}\right), \ldots, V\left(M_{1} \geq M_{k}\right)$

The weight of indices in pairwise comparison matrices is calculated by Eq. (12). Consequently, $W\left(x_{i}\right)$ is calculated using the following Equation:

$W\left(x_{i}\right)=\operatorname{Min}\left\{v\left(S_{i} \geq S_{k}\right)\right\} \quad k=1,2,3, \ldots, n k \neq i$

Following, the weight vector $\left(w^{\prime}\left(X_{i}\right)\right)$ is computed by Eq. (13).

$W^{\prime}\left(X_{i}\right)=\left[W^{\prime}\left(C_{1}\right), W^{\prime}\left(C_{2}\right), W^{\prime}\left(C_{n}\right)\right]^{T}$

Finally, Eq. (14) provides the normal quantities of $W_{i}$ as follows:

$w_{i}=\frac{w_{i}^{\prime}}{\sum w_{i}^{\prime}}$

\subsection{Data collection and questionnaire design}

There are many failures available in different businesses as mentioned before. An initial list of these failures is presented in Table 1. Thereby, to be more accurate and apply the most common failures for final prioritization process, a preliminary filtering of failures is conducted to determine the more common ones in knowledge-based business plans. To do so, a five scale likert questionnaire is designed based on the current failures of business as shown in Table 1. Ten experts with mentionable expertise on the subject were asked to fill the questionnaire and determine the common failures of knowledge-based business plans. The experts are from both academia and industry who are involved in business related activities. They have more than 5 years of experiences in the industry with educational backgrounds in management, business, industrial engineering and knowledge management. The developed questionnaire includes 18 questions which are the representative for the major failures of Table 1. Each question has 5 options to be filled by the experts. Once the common failures of knowledge-based business plans are extracted, the second questionnaire should be designed for FAHP calculations. The FAHP questionnaire includes five linked sections as follows. The first section of this questionnaire includes pairwise comparison of criteria. Bankruptcy, financial failures, purpose loss and unreasonable return are used as the decision criteria to compare the alternatives. Therefore, based on FAHP steps, these criteria should be compared. In other words, the most common failures of knowledge-based business plans are compared using bankruptcy, financial failures, purpose loss and unreasonable return. The second section includes pairwise comparison of alternatives based on the first criteria. Similarly, the third, fourth and fifth sections of questionnaire compare the alternatives based on other remaining criteria. Three experts have contributed in filling the FAHP questionnaire.

The process of data collection includes two phases as follows. As discussed, two questionnaire are designed to collect the required data of this research, The first questionnaire is distributed among ten experts to determine the importance of criteria. The questionnaire's contents were firstly checked and then distributed among afromentioned experts. One of the authors was in charge of data collection and properly addressed all the questions, misunderstanding and other concerns of experts. Following the first phase of data collection process, the second questionnaire was filled by three experts from the case study. The pairwise comparison matrices of the FAHP was translated into the related tables to be filled by experts. Similar to the previous phase, all queries of experts with regard to content, filling process and potential questions were properly addressed by the authors. The considered case study is an investment company with an interest in knowledge-based projects. According to this company, they are interested in investing in knowledge-based projects with the aim of increasing their profit and considering other related concerns of society. However, as these projects might be risky to be chosen, they were interested 
in the obtained results of this research. In other words, the outputs of this study assist them to know more about the most important measures of ranking the failures of knowledge-based business projects. In addition, the obtained results provide the list of potential faults and their ranking to be more investigated in future investments.

\section{Results and discussion}

According to Table 3, F4, F9, F15, F16, and F17 have attained the highest score comparing other failures of the business. Referring to Table 1, these indices stand for poor market research and faulty product concept, trouble among partners, lack of written business plan, lack of managerial experience and ineffective advertising. These values are shown using bold font in Table 3 .

Once the common failures of knowledge-based business are extracted, the second questionnaire should be applied to conduct the FAHP and final prioritization process. The FAHP questionnaire includes five linked sections as follows. The first section of this questionnaire includes pairwise comparison of criteria. In other words, four decision criteria (as shown in second level of Fig. 2) are compared in the first section of the questionnaire. In order to compare the alternatives, the decision criteria which include bankruptcy, financial failures, purpose loss and unreasonable return are applied. Therefore, according to FAHP steps, these criteria are compared. As mentioned, three experts have contributed to fill the FAHP questionnaire. However, as the tables are similar for all three experts, related calculations of the first expert are provided in this study. In other words, all related tables of the first expert in addition to final calculations of remaining two experts are provided. Table 4 compares the decision criteria according to the opinions of the first expert.

The second section includes pairwise comparison of alternative based on first criteria. Similarly, the third, fourth and fifth sections of questionnaire compare the alternatives based on other remaining criteria. Table 5 tabulates the pairwise comparison matrix of alternatives based on bankruptcy criteria. A1, A2, A3, A4 and $A 5$ are the alternatives $(A 1=$ lack of managerial experience, $A 2=$ lack of written business plan, $A 3=$ ineffective advertising, $A 4=$ poor market research, $A 5=$ trouble among partners). As mentioned, related calculations of

Table 3 Data collection to determine the most common failures of knowledge-based business plan

\begin{tabular}{|c|c|c|c|c|c|c|c|c|c|c|c|}
\hline Failures & Expert 1 & Expert 2 & Expert 3 & Expert 4 & Expert 5 & Expert 6 & Expert 7 & Expert 8 & Expert 9 & Expert 10 & Total score \\
\hline $\mathrm{F} 1$ & 2 & 2 & 2 & 2 & 4 & 1 & 2 & 2 & 1 & 2 & 20 \\
\hline $\mathrm{F} 2$ & 2 & 1 & 3 & 2 & 2 & 4 & 4 & 1 & 4 & 2 & 25 \\
\hline F3 & 3 & 1 & 1 & 2 & 3 & 2 & 1 & 1 & 3 & 3 & 20 \\
\hline F4 & 3 & 5 & 2 & 3 & 3 & 3 & 5 & 3 & 2 & 1 & 30 \\
\hline F5 & 4 & 2 & 3 & 2 & 1 & 3 & 2 & 1 & 3 & 1 & 22 \\
\hline F6 & 1 & 1 & 3 & 4 & 2 & 4 & 3 & 2 & 2 & 1 & 23 \\
\hline F7 & 4 & 3 & 1 & 1 & 2 & 1 & 2 & 1 & 1 & 3 & 19 \\
\hline F8 & 2 & 2 & 3 & 2 & 1 & 4 & 3 & 2 & 1 & 1 & 21 \\
\hline F9 & 3 & 5 & 1 & 2 & 3 & 5 & 3 & 3 & 3 & 2 & 30 \\
\hline F10 & 2 & 2 & 3 & 3 & 3 & 1 & 1 & 5 & 4 & 5 & 29 \\
\hline F11 & 2 & 3 & 3 & 1 & 2 & 2 & 1 & 1 & 2 & 2 & 19 \\
\hline F12 & 2 & 2 & 3 & 2 & 2 & 3 & 3 & 2 & 2 & 2 & 23 \\
\hline F13 & 2 & 3 & 2 & 2 & 1 & 1 & 2 & 2 & 2 & 3 & 20 \\
\hline F14 & 1 & 2 & 3 & 2 & 1 & 1 & 2 & 3 & 4 & 2 & 21 \\
\hline F15 & 5 & 4 & 4 & 2 & 4 & 4 & 3 & 4 & 2 & 4 & 36 \\
\hline F16 & 5 & 4 & 5 & 4 & 3 & 4 & 3 & 4 & 3 & 4 & 39 \\
\hline F17 & 4 & 3 & 4 & 5 & 3 & 4 & 2 & 4 & 2 & 3 & 34 \\
\hline
\end{tabular}

Table 4 Pairwise comparison of decision criteria according to expert 1

\begin{tabular}{lllll}
\hline & Bankruptcy & Financial failures & Purpose loss & Unreasonable return \\
\hline Bankruptcy & $(1,1,1)$ & $(1,3 / 2,2)$ & $(3 / 2,2,5 / 2)$ & $(2,5 / 2,3)$ \\
Financial failures & $(1 / 2,2 / 3,1)$ & $(1,1,1)$ & $(1,3 / 2,2)$ & $(1 / 2,1,3 / 2)$ \\
Purpose loss & $(2 / 5,1 / 2,2 / 3)$ & $(1 / 2,2 / 3,1)$ & $(1,1,1)$ & $(1,3 / 2,2)$ \\
Unreasonable return & $(1 / 3,2 / 5,1 / 2)$ & $(2 / 3,1,2)$ & $(1 / 2,2 / 3,1)$ & $(1,1,1)$ \\
\hline
\end{tabular}


Table 5 Pairwise comparison of alternative based on first criteria (expert 1)

\begin{tabular}{llllll}
\hline $\begin{array}{l}\text { Unreasonable } \\
\text { return }\end{array}$ & A1 & A2 & A3 & A4 & A5 \\
\hline A1 & $(1,1,1)$ & $(1,3 / 2,2)$ & $(3 / 2,2,5 / 2)$ & $(3 / 2,2,5 / 2)$ & $(3 / 2,2,5 / 2)$ \\
A2 & $(1 / 2,2 / 3,1)$ & $(1,1,1)$ & $(1,3 / 2,2)$ & $(3 / 2,2,5 / 2)$ & $(2,5 / 2,3)$ \\
A3 & $(2 / 5,1 / 2,2 / 3)$ & $(1 / 2,2 / 3,1)$ & $(1,1,1)$ & $(1,3 / 2,2)$ & $(1 / 2,1,3 / 2)$ \\
A4 & $(2 / 5,1 / 2,3 / 2)$ & $(2 / 5,1 / 2,2 / 3)$ & $(1 / 2,2 / 3,1)$ & $(1,1,1)$ & $(3 / 2,2,5 / 2)$ \\
A5 & $(2 / 5,1 / 2,2 / 3)$ & $(1 / 3,2 / 5,1 / 2)$ & $(2 / 3,1 / 2)$ & $(2 / 5,1 / 2,2 / 3)$ & $(1,1,1)$ \\
\hline
\end{tabular}

Table 6 Pairwise comparison of alternative based on second criteria (expert 1)

\begin{tabular}{llllll}
\hline $\begin{array}{l}\text { Financial } \\
\text { failures }\end{array}$ & A1 & A2 & A3 & A4 & A5 \\
\hline A1 & $(1,1,1)$ & $(1,3 / 2,2)$ & $(3 / 2,2,5 / 2)$ & $(1,3 / 2,2)$ & $(3 / 2,2,5 / 2)$ \\
A2 & $(1 / 2,2 / 3,1)$ & $(1,1,1)$ & $(3 / 2,2,5 / 2)$ & $(3 / 2,2,5 / 2)$ & $(1,3 / 2,2)$ \\
A3 & $(2 / 5,1 / 2,2 / 3)$ & $(2 / 5,1 / 2,2 / 3)$ & $(1,1,1)$ & $(3 / 2,2,5 / 2)$ & $(3 / 2,2,5 / 2)$ \\
A4 & $(2 / 7,1 / 3,2 / 5)$ & $(2 / 5,1 / 2,2 / 3)$ & $(2 / 5,1 / 2,2 / 3)$ & $(1,1,1)$ & $(1 / 2,1,3 / 2)$ \\
A5 & $(2 / 5,1 / 2,2 / 3)$ & $(1 / 2,2 / 3,1)$ & $(2 / 5,1 / 2,2 / 3)$ & $(2 / 3,1,2)$ & $(1,1,1)$ \\
\hline
\end{tabular}

Table 7 Pairwise comparison of alternative based on third criteria (expert 1)
Table 8 Pairwise comparison of alternative based on forth criteria (expert 1)

\begin{tabular}{llllll}
\hline Purpose loss & A1 & A2 & A3 & A4 & A5 \\
\hline A1 & $(1,1,1)$ & $(1 / 2,1,3 / 2)$ & $(1,3 / 2,2)$ & $(1,3 / 2,2)$ & $(1,3 / 2,2)$ \\
A2 & $(2 / 3,1,2)$ & $(1,1,1)$ & $(1 / 2,1,3 / 2)$ & $(3 / 2,2,5 / 2)$ & $(3 / 2,2,5 / 2)$ \\
A3 & $(2 / 3,1,2)$ & $(2 / 3,1,2)$ & $(1,1,1)$ & $(3 / 2,2,5 / 2)$ & $(3 / 2,2,5 / 2)$ \\
A4 & $(1 / 2,2 / 3,1)$ & $(2 / 5,1 / 2,2 / 3)$ & $(2 / 5,1 / 2,2 / 3)$ & $(1,1,1)$ & $(3 / 2,2,5 / 2)$ \\
A5 & $(1 / 2,2 / 3,1)$ & $(2 / 5,1 / 2,2 / 3)$ & $(2 / 5,1 / 2,2 / 3)$ & $(2 / 5,1 / 2,2 / 3)$ & $(1,1,1)$ \\
\hline
\end{tabular}

\begin{tabular}{llllll}
\hline Bankruptcy & A1 & A2 & A3 & A4 & A5 \\
\hline A1 & $(1,1,1)$ & $(1 / 2,1,3 / 2)$ & $(2,5 / 2,3)$ & $(1 / 2,1,3 / 2)$ & $(1 / 2,1,3 / 2)$ \\
A2 & $(2 / 3,1,2)$ & $(1,1,1)$ & $(1 / 2,1,3 / 2)$ & $(3 / 2,2,5 / 2)$ & $(3 / 2,2,5 / 2)$ \\
A3 & $(1 / 3,2 / 5,1 / 2)$ & $(2 / 3,1,2)$ & $(1,1,1)$ & $(1 / 2,1,3 / 2)$ & $(1 / 2,1,3 / 2)$ \\
A4 & $(2 / 3,1,2)$ & $(1 / 2,2 / 3,1)$ & $(2 / 3,1,2)$ & $(1,1,1)$ & $(1,3 / 2,2)$ \\
A5 & $(2 / 3,1,2)$ & $(2 / 5,1 / 2,2 / 3)$ & $(2 / 3,1,2)$ & $(1 / 2,2 / 3,1)$ & $(1,1,1)$ \\
\hline
\end{tabular}

the first expert are shown in these tables. Therefore, Tables 5, 6, 7 and 8 tabulate the pairwise comparisons of alternatives according to the judgments of the first expert.

According to FAHP, pairwise comparison matrices are necessary for final calculations. Consequently, to simplify the process of data collection, the FAHP questionnaires are designed and completed using pairwise comparison matrices. The FAHP calculations are conducted in Matlab software environment. Table 9 tabulates the final result of FAHP model based on the first expert's judgments. According to the obtained result of the first expert, lack of managerial experience is the most important failure of knowledge-based business plans. This is followed by lack of written business plan, ineffective advertising, poor
Table 9 failures ranking based on expert 1 opinion

\begin{tabular}{lll}
\hline Rank & Failures & Score \\
\hline 1 & Lack of managerial experience & 0.332963 \\
2 & lack of written business plan & 0.18687 \\
3 & Ineffective advertising & 0.18294 \\
4 & Poor market research and faulty prod- & 0.15965 \\
& $\quad$ uct concept & \\
5 & Trouble among partners & 0.137577 \\
& Total weight & 1 \\
\hline
\end{tabular}

market research and faulty product concept, and trouble among partners. Having the same steps conducted in 
Table 10 Failures ranking based on expert 2 opinion

\begin{tabular}{lll}
\hline Rank & Failures & Score \\
\hline 1 & Lack of managerial experience & 0.2498 \\
2 & Lack of written business plan & 0.2373 \\
3 & Ineffective advertisement & 0.1790 \\
4 & Poor market research and faulty product & 0.2186 \\
& concept & \\
5 & Trouble among partners & 0.1153 \\
& Total weight & 1 \\
\hline
\end{tabular}

Table 11 failures ranking based on expert 3 opinion

\begin{tabular}{lll}
\hline Rank & Failure & Score \\
\hline 1 & Lack of managerial experience & 0.2218 \\
2 & lack of written business plan & 0.2111 \\
3 & Ineffective advertising & 0.2014 \\
4 & Poor market research and faulty product & 0.1832 \\
& concept & \\
5 & Trouble among partners & 0.1825 \\
& Total weight & 1 \\
\hline
\end{tabular}

Table 12 Inconsistency ratios of experts' judgments

\begin{tabular}{llll}
\hline Expert & Rlg & RIm & $\begin{array}{l}\text { Validation } \\
\text { (Are the val- } \\
\text { ues }<0.1 ?)\end{array}$ \\
\hline Expert1 & 0.073 & 0.004 & YES \\
& 0.09 & 0.018 & \\
& 0.09 & 0.03 & \\
& 0.092 & 0.032 & \\
& 0.096 & 0.022 & \\
Expert2 & 0.01 & 0.02 & YES \\
& 0.078 & 0.028 & \\
& 0.096 & 0.035 & \\
& 0.084 & 0.030 & \\
& 0.095 & 0.034 & YES \\
Expert3 & 0.075 & 0.033 & \\
& 0.098 & 0.046 & \\
& 0.095 & 0.027 & \\
& 0.098 & 0.03 & \\
& 0.097 & 0.032 & \\
\hline
\end{tabular}

Matlab software, Tables 10 and 11 tabulate the obtained results of the second and third experts, respectively.

Commonly, as the quantity of comparison matrices increases, the decision makers might lose the track of their judgments [20]. Therefore, the assigned preference of a specific set of pairwise comparison matrices should be consistent with others. Consequently, it is compulsory to test the consistency of FAHP calculations [49]. Table 12 shows the consistency results of the FAHP. As it is shown, the calculations are valid since the inconsistency ratio is below 0.1 .

Table 13 tabulates the final obtained result of FAHP separated based on each expert. As this study aims to provide a single score for all considered failures of knowledgebased business plans, the average of the judgments of all three experts are applied for prioritization process. Prioritized failures of knowledge-based business are shown in Table 14. Obviously, lack of managerial experience is the major failure of knowledge-based business plans. Lack of written business plan is the second alternative which is followed by ineffective advertising, poor market research and faulty product concept, and trouble among partners. These results are also shown using Fig. 3. Consequently, regarding the obtained results, the lack of managerial experience plays an important role in failures of knowledge-based business plans. Obviously, financial failures and bankruptcy are the direct result of lack of managerial experience.

\section{Concluding remarks}

This study applied a FAHP model to rank the failures of knowledge-based business plans. The study was carried out in three main steps as follows. Firstly, the general failures of businesses were developed from the previous literature. Secondly, the developed failures were investigated with regard to their availability in knowledge-based business plans. Finally, a FAHP model was applied to prioritize the failures of knowledge-based business plan. Based on the obtained results, lack of managerial experience, lack of written business plan, ineffective advertising, poor market research and faulty product concept, and trouble among partners are five main failures of knowledge-based business, respectively.

There are some scientific contributions which are developed in this research. Firstly, this research investigated the literature to find the major criteria to be considered in ranking the different failures of knowledge-based business plans. Secondly, the research determined the most important criteria for investigating the different faults of knowledge-based business plans. Finally, as an important scientific contribution, the prioritized failures of knowledge-based business shown in Table 14 can be considered by managers, practitioners and researchers to be more investigated before the investment process. Lack of managerial experience is the most important issue to be considered by investor as this shortage might cause many issues within or after the investment process. Following, it is very critical for the business developers to 
Table 13 Average weight of alternative

\begin{tabular}{llllll}
\hline & Expert1 & Expert2 & Expert3 & Sum & Average \\
\hline Lack of managerial experience & 0.332963 & 0.2498 & 0.2218 & 0.80456 & 0.2682 \\
Lack of written business plan & 0.18687 & 0.2373 & 0.2111 & 0.63527 & 0.2117 \\
Ineffective advertising & 0.18294 & 0.1790 & 0.2014 & 0.5633 & 0.1877 \\
$\begin{array}{l}\text { Poor market research and faulty } \\
\quad \text { product concept }\end{array}$ & 0.15965 & 0.2186 & 0.1832 & 0.5614 & 0.1871 \\
\begin{tabular}{l} 
Trouble among partners \\
\hline
\end{tabular} & 0.137577 & 0.1153 & 0.1825 & 0.4353 & 0.1451 \\
\hline
\end{tabular}

Table 14 Prioritized failures of knowledge-based business

\begin{tabular}{lll}
\hline Rank & Failures & Weight \\
\hline 1 & Lack of managerial experience & 0.2682 \\
2 & Lack of written business plan & 0.2117 \\
3 & Ineffective advertising & 0.1877 \\
4 & Poor market research and faulty product & 0.1871 \\
& concept & \\
5 & Trouble among partners & 0.1451 \\
& Total & 1 \\
\hline
\end{tabular}

have a written business plans. The oral plans without any documentation might seem to be interesting. However, their problems are revealed once they are converted to written plans. The important role of advertising is shown in this research as ineffective advertising has been ranked as the third important reason of knowledge-based business plans' failure. It is very important for any business to have a Research and Development (R\&D) plan prior and during the investigation. Therefore, the poor market research can cause many issues as it has been selected as the fourth major reason of failures. Following, faulty concept of product and potential issues amongst the partners should be addressed as these issues can cause problems in knowledge-based business plans. Therefore, as a theoretical implication, the obtained results of this study are applicable for researchers to be more investigated as the potential causes of failures in knowledge-based business plans. In addition, the managers can address these concerns with proper investment and consideration. However, although this research has addressed many issues to be considered in the investigated problem, there are some limitation which can be addressed in future studies. These limitations include the low level of knowledge on business plans and how it is different from feasibility studies. In addition, knowledge-based business plans are very new in developing countries. Considering these plans in developing countries provide added-value to both society and the investors. Therefore, the obtained results of the research can be applied in both research and practice. As a research implication, the criteria and the final ranking of failures can be investigated in other business plans. As a practical implication, managers and practitioners can investigate these faults within their companies and provide solution to decrease them. In addition to research and practice, there are some global implications which are not limited to developing countries. As an example, the developed criteria and the prioritized failures might be present in any knowledge-based business plan in developed countries. Therefore, the measures and the final faults can be more investigated in developed countries to be compared with the obtained results of this research. There are some other directions to expand the ideas of this research. For
Fig. 3 Prioritized faults of knowledge-based business plans

\section{Prioritized failures of knowledge-based business plan}

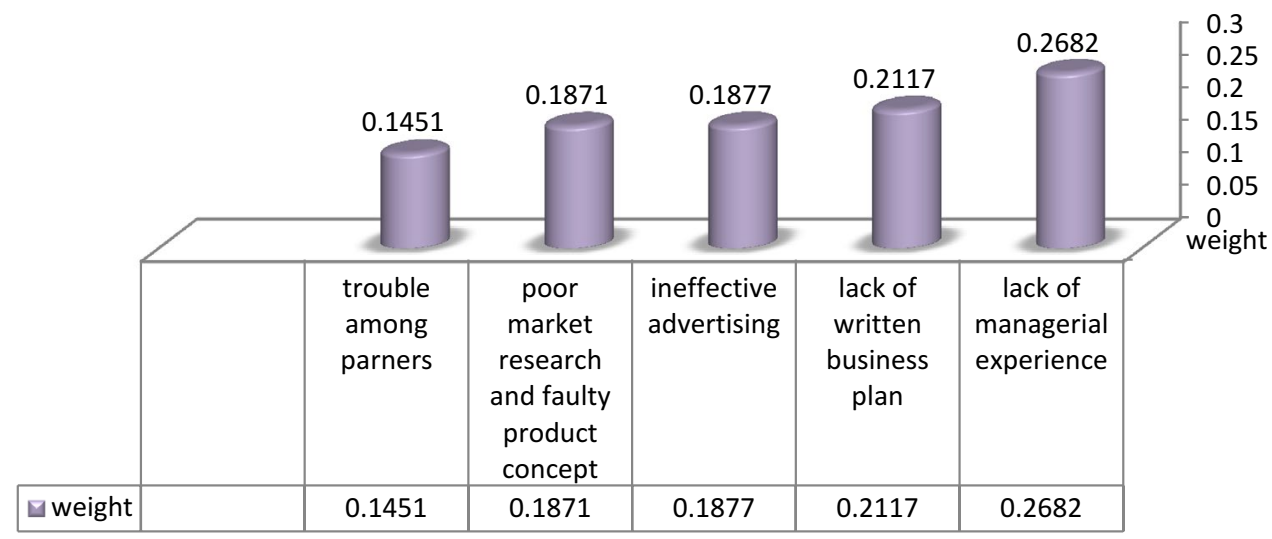


example, the developed research methodology can be applied to prioritize the failures in other types of business plans. In addition, other MCDM techniques can be applied to be compared with FAHP.

Acknowledgements We would like to appreciate the constructive comments of anonymous editors and the reviewers which really improved the quality of papers.

\section{Compliance with ethical standards}

Conflict of interest The authors declare no conflict of interest in publishing this study.

Statement on ethical approval All procedures performed in studies involving human participants were in accordance with the ethical standards of the institutional and/or national research committee and with the 1964 Helsinki declaration and its later amendments or comparable ethical standards. In addition, as the paper has been extracted from a thesis (the student is listed in author list), the ethical issues are approved by the third author (main supervisor). The applied data is anonymized as the questionnaires included no section to record the name of experts.

\section{References}

1. Amankwah-Amoah J, Boso N, Antwi-Agyei I (2018) The effects of business failure experience on successive entrepreneurial engagements: an evolutionary phase model. Group Organ Manag 43(4):648-682

2. Amsden AH, Tschang T, Goto A (2001) Do foreign companies conduct R\&D in developing countries? (No. 14). ADBI Research Paper Series

3. Beckerle P (2016) Practical relevance of faults, diagnosis methods, and tolerance measures in elastically actuated robots. Control Eng Pract 50:95-100

4. Bezerra CG, Costa BSJ, Guedes LA, Angelov PP (2016) An evolving approach to unsupervised and real-time fault detection in industrial processes. Expert Syst Appl 63:134-144

5. Bhattacharjee A, Higson C, Holly S, Kattuman P (2009) Macroeconomic instability and business exit: determinants of failures and acquisitions of UK firms. Economica 76(301):108-131

6. Boso N, Adeleye I, Donbesuur F, Gyensare M (2019) Do entrepreneurs always benefit from business failure experience? J Bus Res 98:370-379

7. Brinckmann J, Dew N, Read S, Mayer-Haug K, Grichnik D (2019) Of those who plan: a meta-analysis of the relationship between human capital and business planning. Long Range Plan 52(2):173-188

8. Calvo-Mora A, Navarro-García A, Periañez-Cristobal R (2015) Project to improve knowledge management and key business results through the EFQM excellence model. Int J Proj Manag 33(8):1638-1651

9. Chang DY (1996) Applications of the extent analysis method on fuzzy AHP. Eur J Oper Res 95(3):649-655

10. Churchill BC (1952) Survival patterns of the postwar business population. Surv Curr Bus 32(12):12-19

11. Cochran $A B$ (1981) Small business mortality rates: a review of the literature. J Small Bus Manag (pre-1986) 19(000004):50
12. Ding SX (2008) Model-based fault diagnosis techniques: design schemes, algorithms, and tools. Springer, Berlin

13. Everett J, Watson J (1998) Small business failure and external risk factors. Small Bus Econ 11(4):371-390

14. Ferreira ADSM, Loiola E, Gondim SMG (2017) Motivations, business planning, and risk management: entrepreneurship among university students. RAI Revista de Administração e Inovação 14(2):140-150

15. Frank PM (1996) Analytical and qualitative model-based fault diagnosis-a survey and some new results. Eur J Control 2(1):6-28

16. Galankashi MR, Helmi SA, Hashemzahi P (2016) Supplier selection in automobile industry: a mixed balanced scorecard-fuzzy AHP approach. Alex Eng J 55(1):93-100

17. Galankashi MR, Helmi SA, Hisjam M, Rahim ARA (2018) Leanness assessment in automotive industry: case study approach. Int J Value Chain Manag 9(1):70-88

18. Galankashi MR, Hisjam M, Helmi SA (2016) Agile supplier selection: a fuzzy analytic hierarchy process (FAHP) approach. In: Proceedings of the sixth international conference on industrial engineering and operations management (IEOM), Kuala Lumpur

19. Galankashi MR, Hisjam M, Helmi SA (2013) Lean supplier selection: a data envelopment analysis (DEA) approach. In: Proceedings of the sixth international conference on industrial engineering and operations management (IEOM), Kuala Lumpur

20. Galankashi MR, Moazzami A, Madadi N, Haghighian Roudsari A, Helmi SA (2013) Supplier selection for electrical manufacturing companies based on different supply chain strategies. Special Edition on Advanced Technique of Estimation Applications in Electrical Engineering, of HCTL Open International Journal of Technology Innovations and Research (IJTIR), pp 10-22

21. Ganguly P (1985) UK small business statistics and international comparisons. Paul Chapman Pub

22. Gaskill LR, Van Auken HE, Manning RA (1993) A factor analytic study of the perceived causes of small business failure. J Small Bus Manag 31:18

23. Graeber AR, Baeck C, Wilmes MJ, Scheiber C, Sinzig W (2013) Analyzing business data for planning applications. U.S. Patent 8,412,549, issued April 2, 2013

24. Gunjal B (2005) Knowledge management: why do we need it for corporates. Malays J Libr Inf Sci 10(2):37-50

25. Hall G, Young B (1991) Factors associated with insolvency amongst small firms. Int Small Bus J 9(2):54-63

26. Harmon $P$ (2019) Business process change: a business process management guide for managers and process professionals. Morgan Kaufmann, Burlington

27. Hemmati N, Rahiminezhad Galankashi M, Imani DM, Farughi H (2018) Maintenance policy selection: a fuzzy-ANP approach. J Manuf Technol Manag 29(7):1253-1268

28. Hennart JF (2019) Digitalized service multinationals and international business theory. J Int Bus Stud 50(8):1388-1400. https ://doi.org/10.1057/s41267-019-00256-2

29. Hohenthal J, Johanson J, Johanson M (2015) Network knowledge and business-relationship value in the foreign market. In: Forsgren $\mathrm{M}$, Holm U, Johanson J (eds) Knowledge, networks and power. Palgrave Macmillan, London. https://doi. org/10.1057/9781137508829_8

30. lerace S, Cavalieri S (2008) Maintenance strategy selection: a comparison between fuzzy logic and analytic hierarchy process. IFAC Proc Vol 41(3):228-233

31. Kazooba CT (2006) Causes of small business failure in Uganda: a case study from Bushenyi and Mbarara towns. Afr Stud Q 8(4):27-35

32. Kim SK, Min S (2015) Business model innovation performance: When does adding a new business model benefit an incumbent? Strateg Entrep J 9(1):34-57 
33. Kusumaningrum I, Hidayat $\mathrm{H}$ (2016) Learning outcomes in vocational education: a business plan development by production-based learning model approach. Int J Environ Sci Educ 11(18):11917-11930

34. Martinez MG, Zouaghi F, Marco TG, Robinson C (2019) What drives business failure? Exploring the role of internal and external knowledge capabilities during the global financial crisis. $J$ Bus Res 98:441-449

35. McKeever M (2016) How to write a business plan. Nolo, Berkeley

36. Mullins J (2012) The new business road test: What entrepreneurs and executives should do before writing a business plan. Pearson, London

37. Moktadir A, Rahman T, Jabbour CJC, Ali SM, Kabir G (2018) Prioritization of drivers of corporate social responsibility in the footwear industry in an emerging economy: a fuzzy AHP approach. J Clean Prod 201:369-381

38. Moktadir MA, Ali SM, Mangla SK, Sharmy TA, Luthra S, Mishra N, Garza-Reyes JA (2018) Decision modeling of risks in pharmaceutical supply chains. Ind Manag Data Syst 118(7):1388-1412

39. Moktadir MA, Ali SM, Paul SK, Shukla N (2019) Barriers to big data analytics in manufacturing supply chains: a case study from Bangladesh. Comput Ind Eng 128:1063-1075

40. Moktadir MA, Rahman T, Sultana R (2017) Selection of best supplier by using AHP tool for managing risk factors in logistics: a case of leather products industry. Ind Eng Manag 6(232):2169-0316

41. Muñoz-Izquierdo N, Segovia-Vargas MJ, Pascual-Ezama D (2019) Explaining the causes of business failure using audit report disclosures. J Bus Res 98:403-414

42. Palacios-Marqués D, Soto-Acosta P, Merigó JM (2015) Analyzing the effects of technological, organizational and competition factors on Web knowledge exchange in SMEs. Telemat Inform $32(1): 23-32$

43. Perry SC (2001) The relationship between written business plans and the failure of small businesses in the US. J Small Bus Manag 39(3):201-208

44. Peterson RA, Kozmetsky G, Ridgway NM (1983) Perceived causes of small business failures: a research note. Am J Small Bus 8(1):15-19
45. Pina K, Tether BS (2016) Towards understanding variety in knowledge intensive business services by distinguishing their knowledge bases. Res Policy 45(2):401-413

46. Rahiminezhad Galankashi M, Helmi SA (2016) Assessment of hybrid Lean-Agile (Leagile) supply chain strategies. J Manuf Technol Manag 27(4):470-482

47. Riis JO, Achenbach $M$, Israelsen $P$, Kyvsgaard Hansen $P$, Johansen J, Deuse J (2017) Dealing with complex and ill-structured problems: results of a Plan-Do-Check-Act experiment in a business engineering semester. Eur J Eng Educ 42(4):396-412

48. Saaty RW (1987) The analytic hierarchy process - what it is and how it is used. Math Model 9(3-5):161-176

49. Saaty TL (2013) Analytic hierarchy process. In: Gass SI, Harris CM (eds) Encyclopedia of operations research and management science. Springer, Boston, pp 52-64. https://www.springer.com/ gp/book/9781402006111

50. Siepel J, Cowling M, Coad A (2017) Non-founder human capital and the long-run growth and survival of high-tech ventures. Technovation 59:34-43

51. Watson J, Everett J (1993) Defining small business failure. Int Small Bus J 11(3):35-48

52. Williams ML (1993) Measuring business starts, success and survival: some database considerations. J Bus Ventur 8(4):295-299

53. Xu Z, Frankwick GL, Ramirez E (2016) Effects of big data analytics and traditional marketing analytics on new product success: a knowledge fusion perspective. J Bus Res 69(5):1562-1566

54. Ziaei F, Baniani AM, Galankashi MR, Ghashami SS, Nargesi ZR (2013) Application of minimax, minsum and analytical hierarchy process for facility location problem. Aust J Basic Appl Sci 7(14):237-245

Publisher's Note Springer Nature remains neutral with regard to jurisdictional claims in published maps and institutional affiliations. 